\title{
Nervous System Hemangiopericytoma
}

\author{
Or Cohen-Inbar
}

\begin{abstract}
The management of patients harboring central nervous system (CNS) hemangiopericytomas (HPCs) is a partially answered challenge. These are rare locally aggressive lesions, with potential for local recurrence, distal neural metastasis (DNM), and extraneural metastasis (ENM). Resection, when feasible, remains the initial treatment option, providing histological diagnosis and immediate relief of tumor-related mass effect. Patients receiving surgery alone or surgery and external beam radiotherapy (EBRT) show improved overall survival (OS) and progression-free survival as compared to those undergoing a biopsy alone $(p=0.01$ and $p=0.02$, respectively). Yet, in many instances, patient and tumor-related parameters preclude complete resection. EBRT or stereotactic radiosurgery (SRS) shares a significant role in achieving local tumor control, not shown to impact OS in HPC patients. The benefits of SRS/EBRT are clearly limited to improved local tumor volume control and neurologic function, not affecting DNM or ENM development. SRS provides acceptable rates of local tumor volume control coupled with treatment safety and a patient-friendly apparatus and procedure. Single-session SRS is most effective for lesions measuring $<2 \mathrm{~cm}$ in their largest diameter (10 $\mathrm{cm}^{3}$ volume), with prescription doses of at $>15 \mathrm{~Gy}$. Systemic HPC disease is managed with various chemotherapeutic, immunotherapeutic, and anti-angiographic agents, with limited success. We present a short discussion on CNS HPCs, focusing our discussion on available evidence regarding the role of microsurgical resection, EBRT, SRS, chemotherapy, and immunotherapy for upfront, part of adoptive hybrid surgery approach or for recurrent HPCs.
\end{abstract}

RÉSUMÉ : L'hémangiopéricytome du système nerveux central. La prise en charge des patients atteints d'un hémangiopéricytome du système nerveux central demeure un défi auquel on n'a pas tout à fait encore répondu. Il s'agit en effet de lésions fulminantes qui présentent un potentiel de récurrence locale mais aussi d'apparition de métastases affectant la partie distale des neurones et de métastases hors neurones. Lorsque cela est possible, la résection constitue la première option thérapeutique. Cette dernière permet d'assurer un diagnostic histologique ainsi qu'un soulagement immédiat de l'effet de masse associé à la tumeur cérébrale. Les patients bénéficiant uniquement d'une intervention chirurgicale ou d'une intervention combinant la chirurgie et la radiothérapie ont montré une amélioration de leur taux de survie globale et de leur taux de survie sans aggravation si on les compare aux autres patients soumis à une seule biopsie (respectivement $\mathrm{p}=0,01$ et $\mathrm{p}=0,02$ ). Dans bien des cas, il est des paramètres se rapportant aux patients et aux tumeurs elles-mêmes qui excluent une résection complète. À cet égard, rappelons qu'une intervention combinant chirurgie et radiothérapie ou bien encore la radiochirurgie stéréotaxique peuvent jouer un rôle clé dans le contrôle d'une tumeur locale, et ce, sans que le taux de survie globale des patients atteints d'un hémangiopéricytome soit affecté. Cela dit, les bénéfices de la radiochirurgie stéréotaxique et d'une intervention combinant chirurgie et radiothérapie demeurent clairement limités à une amélioration du contrôle des tumeurs locales et des fonctions neurologiques et n'ont pas d'impact sur le développement des métastases affectant la partie distale des neurones et des métastases hors neurones. Ajoutons aussi que la radiochirurgie stéréotaxique offre des taux de contrôle des tumeurs locales acceptables en plus de représenter un traitement sécuritaire pour les patients et de sous-tendre l'utilisation de procédures et d'équipements conviviaux. Une simple séance de radiochirurgie stéréotaxique sera particulièrement indiquée dans le cas de lésions mesurant moins de $2 \mathrm{~cm}$ dans leur plus grand diamètre (volume de $10 \mathrm{~cm}^{3}$ ), les doses prescrites étant de $>15 \mathrm{~Gy}$. Un hémangiopéricytome de caractère systémique pourra être traité avec un succès limité au moyen de nombreux agents chimiothérapeutiques, immunothérapeutiques et anti-angiographiques. Nous voulons donc faire ici un bref exposé au sujet des hémangiopéricytomes du système nerveux central. Nous voulons aussi mettre l'accent sur les preuves disponibles concernant l'impact de la résection microchirurgicale, des interventions combinant chirurgie et radiothérapie, de la radiochirurgie stéréotaxique, de la chimiothérapie et de l'immunothérapie dans le cadre d'une approche chirurgicale hybride initiale pour des cas récurrents d'hémangiopéricytomes.

Keywords: Hemangiopericytoma, Adoptive hybrid surgery, Stereotactic radiosurgery, EBRT

doi:10.1017/cjn.2019.311

Can J Neurol Sci. 2020; 47: 18-29

\section{INTRODUCTION}

Hemangiopericytoma (HPC) is a rare, aggressive, and highly vascularized mesenchymal tumor. Many features of HPC resemble meningiomas, ${ }^{1-4}$ which explains why these were initially classified as angioblastic meningiomas by Cushing and Eisenhardt. ${ }^{5}$ HPCs are derived from fibro-histiocytic precursor cells, the pericytes of Zimmerman. ${ }^{6}$ These are immature spindle cells with contractile properties that attach to capillary walls. ${ }^{7}$ The cells of Zimmerman are crucial in mechanically supporting the capillaries, aiding thus in luminal size changes to different physiological challanges. ${ }^{8,9}$
HPC is a systemic neoplasm, frequently involving the skin and musculoskeletal system. ${ }^{9}$ Intracranial cavity involvement is rare in HPC, constituting approximately $0.4 \%$ of all intracranial lesions

From the Department of Neurological Surgery, University of Pittsburgh, Cumberland, MD, USA; Department of Neurological Surgery, University of Virginia, Charlottesville, VA, USA

Received April 17, 2019. Final Revisions Submitted September 13, 2019. Date of Acceptance October 8, 2019.

Correspondence to: Or Cohen-Inbar, Department of Neurological Surgery, University of Pittsburgh, 12502 Willbrook Road, Cumberland, MD 21502, USA. Email: ocoheninbar@wmhs.com 
and $2.4 \%$ of meningeal lesions. ${ }^{3,7,10,11}$ The first report of an intracranial HPC can be dated to 1954 , by Begg and Garret, ${ }^{12}$ but these were classified as a distinct pathological entity by the World Health Organization (WHO) only in 1993, based on clinical, immunohistochemical, ultrastructural, and genetic features. $^{13-15}$ The 2016 WHO classification defines the solitary fibrous tumors (SFTs)-HPC entities on a single spectrum with a single grading system. This is based on unique genetic events occurring in these pathologies, that is, the fusion of $N A B 2$ and STAT6 genes. ${ }^{16}$ In addition, histological parameters of proliferation (MIB-1 index) $)^{17,18}$ and classical features of malignancy (cellular atypia, necrosis, mitotic figures, etc. $)^{4}$ are known negative prognostic factors in SFT-HPCs. HPCs have a slight male predominance, ${ }^{4}$ and a mean age of $38-42$ years at presentation. Most intracranial HPCs are supratentorial $(62 \%) ., 19,20$

HPCs are notorious for their "aggressive" biology, featuring high recurrence rates (reaching 91\% after surgical resection in some reports), ${ }^{18}$ distant intracranial and neural axis metastasis (DNM), and extraneural metastasis (ENM), appearing even after a gross-total resection (GTR) was achieved. The cumulative risk of ENM reaches as high as $70 \%$ in 15 years. $^{2-4,6,10,21-26}$ The incidence of both DNM and ENM increases with time, serving as a negative prognostic factor. ${ }^{27}$

Treatment of HPC is multidisciplinary and challenging. Micro-surgical resection, when feasible, still serves as the initial treatment of choice for large HPCs. ${ }^{28}$ Microsurgical resection offers several benefits for intracranial HPC, including the immediate relief in the clinical manifestations of related mass effect, as well as provides tissue diagnosis and characterization. Yet, the florish "staghorn" vascular nature of HPCs and frequent involvement of adjacent meningeal dural venous sinuses and cranial osseous components can make surgical GTR a formidable and at times unrealistic goal. ${ }^{10}$ Most long-term follow-up reports note that the majority of HPC patients require a multidisciplinary, doctrine crossing, approach with different modalities serving as "salvage" or "complimentary" to prevent recurrence or progression of the HPC disease. ${ }^{10,11,26-29}$ We present a short two-part discussion on central nervous system (CNS) HPCs, reviewing current treatment paradigms. In Part I, we focus our discussion on the challenges of intracranial HPC.

\section{Imaging Features}

\section{Cranial Hemangiopericytomas}

The radiographic differentiation of intracranial HPCs from a meningioma is pivotal in the preoperative management planning and choice of surgical approach, owing to the higher risk of severe bleeding and of local recurrence, even after a "conventional" Simpson grade-I GTR. ${ }^{30}$ Radiographic similarities to meningiomas are profound, and distinguishing HPCs can be challenging. HPCs typically feature lobulated margins, frequent internal serpentine flow-related signal voids, and absent calcifications. This is different from meningiomas, which typically have smooth margins, no flow voids, and abundant calcifications (20-25\%). ${ }^{31}$ HPCs typically feature a paucity of peritumoral edema and a unique distinct angio-architectural pattern. This pattern involves a dual blood supply from intracranial and extracranial blood vessels. Unlike in meningiomas, the dominant blood supply in HPCs typically arises from the internal carotid artery (ICA) or vertebral artery (VA) branches [rather than the external carotid artery (ECA) in meningiomas] which manifests in numerous corkscrew vessels seen arising from a main arterial feeder within the tumor on digital substraction angiography (DSA). ${ }^{30}$ This DSA feature results in a long-lasting contrast enhancement pattern, compared to the typical sunburst ECA-related DSA pattern seen in meningiomas. ${ }^{32}$

The MRI appearance of intracranial HPCs may be similar to that of meningiomas. Unique HPC-related features include a narrow base of attachment, an irregular/multilobulated cross-leaf growth, the absence of intratumoral calcifications, the absence of related osseous hyperostosis, ${ }^{33}$ bone erosion, and heterogeneous gadolinium contrast enhancement. ${ }^{34}$ Cranial HPCs are typically isointense with gray matter on both T1- and T2-weighted MRI sequences. Mixed signals when noted were shown to be associated with the grade-III (anaplastic) aggressive HPC type. ${ }^{33} \mathrm{~A}$ "dural tail" is seen in $30 \%$ of grade-II patients. ${ }^{34}$ The grade-III anaplastic HPC variant is marked by the presence of necrosis, cystic changes, and extensive peritumoral edema. ${ }^{33}$ Diffusionweighted imaging in grade-III HPCs is marked by higher ADC values compared to grade-II HPCs, meningioma, or with the normal surrounding brain. ${ }^{34,35}$ Whole-tumor histogram analysis of ADC maps may be a useful tool for differential diagnosis, with ADCmin and ADC5 being potential parameters. ${ }^{36}$

\section{Spinal Hemangiopericytomas}

Spinal HPCs can be divided into intradural (ID) and extradural (ED) lesions. The ID HPCs in turn, can be intramedullary (IM) or extramedullary (EM). ${ }^{37}$ The ED HPCs are further classified as either dural-based or primarily osseous. ${ }^{38}$ These distinctions, maybe in spinal HPCs more than cranial HPCs, have a dramatic and significant influence on the prospect of attaining a GTR, risk of neurological morbidity, recurrence, and so on. Radiographic features of spinal HPCs include a multilobular or "dumbbell"shaped mass, expanding and eroding adjacent vertebral cortical bone. These lesions are typically hypointense on T1WI, moderately hyperintense on T2WI, with an homogeneous gadolinium enhancement pattern, at times with internal vessel voids (similarly to the cranial HPCs). ${ }^{39-41}$ Advanced dynamic MRI-imaging techniques, such as diffusion-weighted imaging (DWI) and diffusion tensor imaging (DTI), have been employed in the evaluation of spinal lesions. ${ }^{40}$ DTI and fiber tractography analyses allow for a better preoperative diagnosis. A better understanding of the patient's altered white matter microanatomy and tracts in relation to the lesion is provided (for ID-IM and ID-EM HPCs), more so than a conventional MRI study, in planning the surgical intervention and counseling the patient on potential risks and accepted post-operative morbidity. ${ }^{42}$

Computed tomography (CT) and myelography are less frequently utilized modalities nowadays for ID-IM or ID-EM HPCs, yet may still have a role in assessing the osseous components and the need for spinal stabilization upon resection (ED HPCs or those spanning both compartments). Spinal positron emission tomography/CT using either fludeoxyglucose or 11(C)-methionine has shown efficacy and a potential role in the evaluation of high-grade malignant ID-IM lesions. ${ }^{43}$ Protoporphyrin IX (PpIX) fluorescence induced by 5-aminolevulinic acid (5-ALA) was recently shown relevant and helpful in the detection of potential spinal-HPC tumor residual during microsurgical resection. ${ }^{44}$ 


\section{Multimodal Management}

The management of intracranial HPCs, being a rare entity, is not referred to in the National Comprehensive Cancer Network Clinical Practice Guidelines. ${ }^{45}$ Clinical standard guidelines are thus lacking, and treatment plans are typically based on single institution retrospective small series, ${ }^{46,47}$ multicenter small cohorts, and Surveillance, Epidemiology and End Results (SEER) analyses. ${ }^{48-50}$ Multimodal treatment consisting of GTR (when feasible) and external beam radiotherapy (EBRT) is considered standard care, noted to convey an average survival of 84 months from the time of diagnosis, not accounting for neurological and overall morbidity. ${ }^{51}$ The recurrence rates after GTR and EBRT are reported to be high, reaching $30 \%$. $^{25}$ The literature on spinal HPCs is composed mainly of case reports or short case series with approximately 112 cases of primary spinal HPCs published to date (all locations). A comprehensive review of the literature is shown in Table $1 .^{52-96}$ In addition, the significant incidence of operative neurological morbidity, coupled with the high recurrence and progression rates, optimal management is still a relevant open question.

The clinical presentation of spinal HPC is nonspecific, depending mainly on lesion location, lesion size, the main compartment involved (ID vs. ED), the extent of spinal cord, and nerve root compression or involvement, not differing with various HPC histologic grades. ${ }^{97}$ Neurological deficits and weakness are common for ED HPCs owing to the diminishing ED compartment, similarly to other spinal ID lesion types..$^{25,68,86,98}$ Primary osseous spinal HPCs conversely typically manifest with pain and mass effect, owing to the lesions expending into the paravertebral gutter region and cortical bone. 99

Formulating an optimal hybrid treatment approach to recurrence and progression is another such unmet challenge. Adjuvant and neo-adjuvant chemotherapy, ${ }^{47,100}$ immunotherapy, or endovascular embolization has shown limited benefit. ${ }^{17,100}$ We will shortly discuss each treatment modality in the battle against intracranial HPCs.

\section{Microsurgical Resection}

\section{Cranial Hemangiopericytomas}

Microsurgical resection offers the benefits of attaining a definite histopathological tissue diagnosis confirmation and analysis coupled with immediate alleviation of tumor-related mass effect. Achieving a GTR at the first operation was shown to be strongly associated with the prolongation of overall survival (OS) and progression-free survival (PFS) in intracranial HPC. $^{3,10,17,25,29,46,101,102}$ Still, microsurgical resection has been shown to provide poor long-term control of intracranial disease when employed solely, despite being considered as the treatment of choice. , $3,10,28$ In many cases, tumor location and neuroanatomical features may not allow a GTR. HPC of the skull-base not allowing dural resection, lesions involving the cavernous sinus or other dural venous sinuses not allowing tumor GTR with margins, HPC encroaching or casting critical neurovascular structures such as cranial nerves, major arterial branches are a few such limitations. The staggering reported surgical mortality rates for these lesions reach as high as 9-24\%, much higher when neurological operative morbidity is reviewed and factored in. ${ }^{10,19,27,28,103}$ Such figures are considered unacceptable in present-day neurosurgery and neuro-oncology practices, which resulted in many surgeons dithering from attaining a GTR in such cases. Of note, even when GTR is attained, curing HPC is challenging with surgery alone due to HPCs' propensity for recurrence, DNM, and ENM. ${ }^{104}$

Rutkowski et al. ${ }^{29}$ reported a large intracranial HPC's cohort of 563 patients in 2010 , trying to define important prognostic factors affecting mortality. Overall median survival reported was 13 years, with a 1-, 5-, 10-, and 20-year survival rates of 95\%, 82\%, 60\%, and $23 \%$, respectively. ${ }^{29}$ GTR achieved in surgery was noted to correlate with a median survival of 13 years, compared to the STR cohort having a median survival of 9.75 years. A complete, extended GTR (Simpson Grade I resection) was noted to be associated with improved PFS. STR was shown to correlate with high recurrence/progression rates (approaching 100\%). ${ }^{46,105}$ The median time to local recurrence was reported to range 12-96 months with higher numbers (lower recurrence rates) in studies employing a multimodality treatment approach. ${ }^{17,26}$ Multiple microsurgical resections are feasible on occasion, yet the summated appreciable morbidity associated with each resection makes this option less attractive to both surgeons and patients. ${ }^{10}$

Melone et al. ${ }^{7}$ reported a single center-based cohort of 36 patients with HPCs in 2014, with all initially undergoing a microsurgical resection. At a median follow-up duration of 118 months, the median OS was 84 months. The actuarial survival rates at 5 and 10 years were $94 \%$ and $72 \%$, respectively. GTR was reported in $70 \%$ of patients at the initial surgery, and adjuvant EBRT was administered to $37 \%$ of GTR and $78 \%$ of STR patients. Patients who received STR were treated with SRS (50\%) or proton beam therapy (50\%) as well. Patients who underwent GTR had significant longer OS and PFS as compared to patients who underwent a STR $\left(p=0.047\right.$ and $p=0.0025$, respectively). ${ }^{7}$ The reported local recurrence rates range $26-80 \%$, depending on multiple factors, such as the extent of resection (GTR vs. STR) and length of follow-up, adjuvant RT/SRS..$^{2-4,10,27}$ Dufour et al. reported in 2001 a very high $88 \%$ recurrence rate after microsurgical resection alone. This figure dropped to $12.5 \%$ with the addition of EBRT. ${ }^{25}$ Guthrie et al. reported that the addition of adjuvant EBRT after resection increased PFS and OS from 34 and 62 months to 75 and 92 months, respectively. ${ }^{3}$ Adjuvant EBRT or SRS after a GTR was not shown to improve OS significantly, yet still improved local tumor control rates. ${ }^{26,28,47,50}$ Other reports did not show any improvement in either OS or PFS. ${ }^{22,98,106}$

The current literature is still conflicted as to what degree the extent of resection correlates with the rate of recurrence, incidence of DNM, or response to adjuvant treatment. ${ }^{47}$ It seems that a micro-surgical resection should ideally be carried out to the point of maximal safe reduction in tumor volume, while preserving neurological function. Modern treatment approaches employ the adoptive hybrid surgery (AHS) approach (planned subtotal resection followed with interval planned SRS), which allows for the preoperative planning of the extent of resection, the irradiated target volume, and other related parameters. ${ }^{107}$

\section{Spinal Hemangiopericytomas}

Li et al. ${ }^{97}$ recently reported a cohort of 94 patients operated for spinal HPC. In this report, an alarming and staggering overall $50 \%$ recurrence rate was noted. Recurrence was highest in HPCs spanning both compartments (ID + ED HPCs), reaching as high as $75 \%$. Isolated ID HPCs had a lower yet still significant $38.5 \%$ 


\section{Table 1: Hemangiopericytoma of the spine literature review}

\begin{tabular}{|c|c|c|c|c|c|c|c|c|c|c|}
\hline Author & Year & Age & Sex & Level & ED/ID & Surgery & Adjuvant therapy & Follow-up (year) & Local recurrence & ENM \\
\hline Schirger $^{52}$ & 1958 & 33 & $\mathrm{~F}$ & $\mathrm{~T} 2$ & ED & + & - & 1 & + & \\
\hline \multirow[t]{2}{*}{ Kruse $^{53}$} & \multirow[t]{2}{*}{1961} & 22 & $\mathrm{~F}$ & $\mathrm{~L}$ & - & + & - & 5 & - & \multirow[t]{2}{*}{ Femur } \\
\hline & & 53 & $\mathrm{M}$ & $\mathrm{C} 3$ & ID & + & RT & 4 & + & \\
\hline \multirow[t]{3}{*}{ Pitlyk $^{54}$} & \multirow[t]{3}{*}{1965} & 60 & $\mathrm{M}$ & $\mathrm{C} 4$ & ID & + & - & 2 & + & \\
\hline & & 39 & $\mathrm{M}$ & $\mathrm{T} 8$ & ID & + & - & 10 & - & \\
\hline & & 49 & $\mathrm{~F}$ & C3 & ID & + & - & 18 & + & \\
\hline Kriss $^{55}$ & 1968 & 16 & $\mathrm{M}$ & C6-C7 & $\mathrm{ED}$ & + & RT & 0.75 & - & \\
\hline Fathie $^{56}$ & 1970 & 21 & $\mathrm{M}$ & $\mathrm{T} 6$ & ED & + & - & & & \\
\hline Gerner $^{57}$ & 1974 & 62 & $\mathrm{M}$ & L5 & ED & + & $\mathrm{RT}$ & & & \\
\hline \multirow[t]{2}{*}{$\operatorname{Scott}^{58}$} & \multirow[t]{2}{*}{1974} & \multirow[t]{2}{*}{38} & \multirow[t]{2}{*}{$\mathrm{M}$} & T12-L1 & & + & + & 3 & \multirow[t]{2}{*}{+} & \multirow[t]{2}{*}{ Skull } \\
\hline & & & & $\mathrm{C}$ & & + & - & & & \\
\hline \multirow[t]{2}{*}{ Harris $^{59}$} & \multirow[t]{2}{*}{1978} & 28 & $\mathrm{M}$ & $\mathrm{C} 2-\mathrm{C} 6$ & $\mathrm{ED}$ & + & $\mathrm{RT}$ & 5 & - & \\
\hline & & 65 & $\mathrm{~F}$ & L2 & ED & + & RT & 4 & - & \\
\hline Stern $^{60}$ & 1980 & 31 & $\mathrm{~F}$ & C6 & $\mathrm{ED}$ & + & - & 1 & - & \\
\hline \multirow[t]{2}{*}{ Cappabianca $^{61}$} & \multirow[t]{2}{*}{1981} & 52 & $\mathrm{~F}$ & C6 & ED & + & - & 0.1 & - & \\
\hline & & 36 & $\mathrm{~F}$ & $\mathrm{C} 5$ & $\mathrm{ED}$ & + & - & 2 & - & \\
\hline \multirow[t]{4}{*}{ Muraszko $^{62}$} & \multirow[t]{4}{*}{1982} & 15 & $\mathrm{M}$ & $\mathrm{T} 12$ & $\mathrm{ED}$ & + & $\mathrm{RT}$ & & 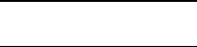 & \\
\hline & & 11 & $\mathrm{~F}$ & $\mathrm{~T} 11$ & $\mathrm{ED}$ & + & RT & 6 & + & \\
\hline & & 41 & $\mathrm{~F}$ & L2 & ED & + & - & & 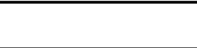 & \\
\hline & & 30 & $\mathrm{M}$ & L3 & ID & + & RT & 12 & + & \\
\hline \multirow[t]{2}{*}{ Ciappetta $^{63}$} & \multirow[t]{2}{*}{1985} & 48 & $\mathrm{M}$ & $\mathrm{C} 4$ & ID & + & - & 7 & + & \\
\hline & & 36 & $\mathrm{~F}$ & C6 & ED & + & RT & 2 & - & \\
\hline Bridges $^{64}$ & 1988 & 25 & $\mathrm{M}$ & $\mathrm{S} 1$ & ED & + & RT & 0.75 & - & \\
\hline Salvati ${ }^{65}$ & 1991 & 39 & $\mathrm{~F}$ & L1-L3 & ED & + & RT & 10 & - & \\
\hline Nonaka $^{66}$ & 1998 & 40 & $\bar{F}$ & $\mathrm{~T} 8$ & & STR & + & 2 & + & Bones, lung \\
\hline Akhaddar $^{67}$ & 2002 & 39 & $\mathrm{M}$ & T4-T6 & ED & + & RT & 3 & - & \\
\hline Betchen $^{68}$ & 2002 & 31 & $\mathrm{M}$ & $\mathrm{L} 4$ & ID & + & - & 0.5 & - & \\
\hline $\mathrm{Ijiri}^{69}$ & 2002 & 39 & $\mathrm{~F}$ & L1-L2 & $\mathrm{ED}$ & + & - & 2 & - & \\
\hline \multirow[t]{2}{*}{ Woitzik $^{70}$} & \multirow[t]{2}{*}{2003} & \multirow[t]{2}{*}{40} & \multirow[t]{2}{*}{$\bar{F}$} & C6-t2 & & GTR & + & \multirow[t]{2}{*}{1} & \multirow[t]{2}{*}{-} & Liver, femur, iliac \\
\hline & & & & L2 & & - & + & & & \\
\hline Mohammadianpanah $^{71}$ & 2004 & 21 & $\mathrm{M}$ & $\mathrm{T} 2$ & ED & STR & $\mathrm{RT}, \mathrm{CT}$ & & & \\
\hline $\mathrm{Lee}^{72}$ & 2006 & 48 & $\mathrm{~F}$ & C6-C7 & & STR & + & 0.7 & - & - \\
\hline Zhao $^{73}$ & 2007 & $\mathrm{~N}=23$ & & $\mathrm{C}=10, \mathrm{~T}=9$ & $\mathrm{ED}=19$ & & $\mathrm{RT}=7$ & & $50 \% \mathrm{ID}$ & \\
\hline & & & & $\mathrm{L}=3, \mathrm{~S}=1$ & $\mathrm{ID}=4$ & & . & & $73 \% \mathrm{ED}$ & \\
\hline Kashiwazaki $^{74}$ & 2007 & 31 & $\mathrm{M}$ & T4-T6 & ID & + & - & 3 & - & \\
\hline Kumar $^{75}$ & 2007 & 16 & $\mathrm{~F}$ & T4-T5 & ED & + & RT & 0.75 & - & \\
\hline
\end{tabular}




\begin{tabular}{|c|c|c|c|c|c|c|c|c|c|c|}
\hline Author & Year & Age & Sex & Level & ED/ID & Surgery & Adjuvant therapy & Follow-up (year) & Local recurrence & ENM \\
\hline Taniura $^{76}$ & 2007 & 30 & $\mathrm{~F}$ & L4-S1 & & STR & + & 1 & - & - \\
\hline $\mathrm{Chou}^{77}$ & 2009 & 80 & $\mathrm{M}$ & $\mathrm{T} 10$ & ID & + & - & 3 & - & \\
\hline $\mathrm{Hogle}^{78}$ & 2009 & 54 & $\mathrm{M}$ & L4-L5 & ID & + & RT & & - & \\
\hline $\mathrm{Cole}^{79}$ & 2009 & 36 & $\mathrm{~F}$ & $\mathrm{C} 3$ & & GTR & + & 4 & + & Liver \\
\hline Fukuda $^{80}$ & 2010 & 36 & $\mathrm{M}$ & $\mathrm{T} 10$ & & GTR & - & 3 & - & - \\
\hline Moscovici $^{81}$ & 2011 & 20 & $\mathrm{M}$ & T9-T10 & ID & + & - & 2 & - & \\
\hline Ackerman $^{82}$ & 2011 & 58 & $\mathrm{M}$ & $\mathrm{T} 10$ & ID & + & - & & - & \\
\hline Santillan $^{83}$ & 2011 & 61 & $\mathrm{~F}$ & $\mathrm{C} 2$ & ED & + & $\mathrm{RT}$ & 0.25 & & \\
\hline Torigoe $^{84}$ & 2012 & 51 & $\mathrm{~F}$ & T6-T7 & ID & + & - & 5 & + & \\
\hline Nakashima $^{85}$ & 2013 & 51 & $\mathrm{~F}$ & $\mathrm{C} 3-\mathrm{C} 4$ & $\mathrm{ID}+\mathrm{ED}$ & + & - & 9 & + & \\
\hline \multirow[t]{4}{*}{ Shirzadi ${ }^{86}$} & \multirow[t]{4}{*}{2013} & 27 & $\mathrm{~F}$ & T7-T8 & ID & + & - & 3 & - & \\
\hline & & 56 & $\mathrm{M}$ & $\mathrm{C} 1-\mathrm{C} 3$ & ID & + & - & 3 & + & \\
\hline & & 57 & $\mathrm{M}$ & T9-T10 & ID & + & $\mathrm{RT}$ & 3 & - & \\
\hline & & 49 & $\mathrm{M}$ & T8-T10 & $\mathrm{ED}$ & + & - & 4 & + & \\
\hline $\operatorname{Drazin}^{87}$ & 2013 & 56 & $\mathrm{M}$ & PF-C4 & ID & + & RT & 5 & - & \\
\hline $\mathrm{Lee}^{88}$ & 2013 & 21 & $\mathrm{M}$ & $\mathrm{C} 1-\mathrm{C} 2$ & ID & + & - & 2 & - & \\
\hline \multirow[t]{3}{*}{$\mathrm{Liu}^{89}$} & \multirow[t]{3}{*}{2013} & \multirow[t]{3}{*}{26} & $\mathrm{M}=14$ & $\mathrm{C}=9$ & $\mathrm{ID}=10$ & + & $\mathrm{RT}=22$ & & \multirow[t]{3}{*}{19 Pts } & \\
\hline & & & \multirow[t]{2}{*}{$\mathrm{F}=12$} & $\mathrm{~T}=7$ & $\mathrm{ED}=10$ & & $\mathrm{CT}=2$ & & & \\
\hline & & & & $\mathrm{L}=5$ & & & & & & \\
\hline Zhang $^{39}$ & 2014 & 43 & $\mathrm{M}$ & C6-T2 & ED & + & - & 1 & - & \\
\hline Ramdasi $^{38}$ & 2014 & 28 & $\mathrm{M}$ & $\mathrm{C} 3$ & ED & + & RT & 1 & - & \\
\hline Jayashankar $^{90}$ & 2014 & 16 & $\mathrm{~F}$ & T5-T6 & ED & + & - & & + & \\
\hline Kaur $^{91}$ & 2014 & 16 & $\mathrm{M}$ & T9 & ID & + & $\mathrm{RT}$ & 5 & - & \\
\hline \multirow[t]{2}{*}{ Türk $^{92}$} & \multirow[t]{2}{*}{2015} & 19 & $\mathrm{~F}$ & $\mathrm{C} 1-\mathrm{C} 2$ & ID & + & - & & - & \\
\hline & & 15 & $F$ & T9-T10 & ID & + & - & & - & \\
\hline \multirow[t]{5}{*}{$\operatorname{Das}^{93}$} & \multirow[t]{5}{*}{2015} & 50 & $\mathrm{M}$ & C4-C5 & ID & + & $\mathrm{RT}+\mathrm{CT}$ & 2 & - & \\
\hline & & 34 & $\mathrm{M}$ & T8-T10 & ID & + & $\mathrm{RT}+\mathrm{CT}$ & 2 & - & \\
\hline & & 37 & $\mathrm{~F}$ & T7-T9 & ID+ED & + & - & 1 & - & \\
\hline & & 12 & $\mathrm{~F}$ & T11-L1 & ID & + & RT & 0.75 & - & \\
\hline & & 37 & $\mathrm{M}$ & C5-C6 & $\mathrm{ED}$ & + & $\mathrm{RT}+\mathrm{CT}$ & 5 & + & \\
\hline Chew $^{94}$ & 2017 & 63 & $\mathrm{M}$ & T9 & ID & + & - & 1 & - & \\
\hline \multirow[t]{3}{*}{ Kweh $^{95}$} & \multirow[t]{3}{*}{2018} & \multirow[t]{3}{*}{55} & \multirow[t]{3}{*}{$\mathrm{M}$} & \multirow[t]{3}{*}{$\mathrm{C} 1, \mathrm{PF}$} & & + & - & 17 & + & \\
\hline & & & & & & + & - & 5 & + & \\
\hline & & & & & & GTR & SRS & 1 & - & \\
\hline Sweid $^{96}$ & 2019 & 46 & $\mathrm{~F}$ & $\mathrm{C}, \mathrm{T} 1, \mathrm{~T} 4$ & $\mathrm{ED}$ & + & RT & 7 & - & - \\
\hline $\mathrm{Li}^{97}$ & 2019 & 35 & $\mathrm{~F}$ & T6-T7 & & GTR & - & 1.15 & - & - \\
\hline
\end{tabular}


local recurrence, and isolated ED had a $44.8 \%$ recurrence rates after a seemingly GTR.$^{97}$ Some authors advocate for an extended GTR approach (entailing resection of the peri-lesional neighboring dura as well) for spinal HPCs in order to prevent local recurrence of metastases. ${ }^{47,69,85,100-102}$ Still, other authors report a much less significant role for GTR. Liu et al. ${ }^{89}$ reported in 2013 a series of 26 patients operated for spinal HPCs in which GTR did not influence OS or PFS. ${ }^{89}$

It is misleading, to some extent, to discuss operative outcome in all-locations spinal HPC together. Lumping tumors in these different compartments together results in a negative bias toward "simpler" lesions. Surgical morbidity for a small osseous, vertebral body-centered ED-HPC is very different clinically and surgically from a large ID-IM HPC. Preoperative electrophysiological evaluation and functional imaging studies as well as intra-operative electrophysiological monitoring are crucial and indispensable. No such surgical endeavor should be undertaken without these measures. Thus, a GTR can be attempted for spinal ED-HPC or ID-EM HPC lesions having clear margins, serving to relieve tumor-related mass effect and neurological morbidity related to direct pressure. An AHS ${ }^{107}$ approach seems prudent for lesions enveloping functional nerve roots or vascular structures (ID-EM or ID-IM). In this approach a planned STR is followed with SRS or RT, reported to reduce recurrence rates and improve OS in spinal HPCs. ${ }^{19,25,108,109}$

\section{Chemotherapy/Immunotherapy/Embolization}

Many chemotherapeutic agents and combinations have been tested, yet an effective drug regimen against HPC is still lacking. ${ }^{110}$ Chamberlain et al. reported in 2008 the use of sequential multiple drug regimens in a cohort of 15 patients with recurrent HPCs who received adjuvant EBRT. ${ }^{53}$ In their report, first line drugs consisted of cyclophosphamide, doxorubicine, and vincristine (CAV). Second-tier drugs were alpha-interferon and then ifosfamide, cisplatin, and etoposide (ICE), in case of subsequent recurrence/failure. A few temporary responses were noted with the CAV regimen, and the OS was 14 months. ${ }^{111}$ Pathologic studies on resected HPC specimens allowed Pierscianek ${ }^{112}$ to demonstrate upregulation of several key signaling pathway markers, including VEGF-VEGFR 2, EphrinB2-EphB4, and DLL4-Notch. Reported in 2016, findings were not different between HPC grade-II or grade-III. These markers may serve as potential targets for therapy, especially considering the known vascular nature of this tumor.

Angiogenic pathway studies paved the way to initial testing of bevacizumab, a monoclonal anti-VEGFR antibody commonly used for the treatment of colorectal cancer and recurrent glioblastoma in intracranial HPC. ${ }^{112}$ Initial studies show activity against HPCs when administered alone ${ }^{29,113-115}$ or in combination with temozolomide. ${ }^{116}$ Tyrosine kinase inhibitors targeting either EphA2 or EphB4 are another potential therapeutic venue. ${ }^{117}$

Preoperative embolization of tumor-related feeding vessels (similar to common practice in meningioma surgery, embolizing ECA vessels) can prove helpful in controlling operative bleeding. Still, such preoperative embolization plays a limited role in intracranial HPC management due to these tumors' tendency to parasitize and invade feeding cortical vessels from both the ECA and ICA. Such angioarchitecture does not allow asymptomatic vessel sacrifice. $^{10,47}$

\section{External Beam Radiotherapy}

The use of EBRT in HPCs postoperatively is widely accepted due to high recurrence rates after surgery alone. ${ }^{24}$ The first application of EBRT for HPCs can be traced back to a report from 1974 by Dube and Paulson, where the authors reported a complete tumor response. ${ }^{118}$ Mira et al. reported in 1977 a short series of 11 HPC patients treated with over 29 courses of EBRT, noting a positive clinical response in 26 of 29 courses. ${ }^{119}$ EBRT was reported to decrease local recurrence rates to $12.5 \%$ after a fractionated dose of 50-64 Gy. These figures contrast an $88 \%$ recurrence rate after GTR alone. ${ }^{25}$ Some authors reported a role of EBRT as neoadjuvant therapeutic approach as well, namely prior to resection, ${ }^{120}$ presumably by reducing tumor vascularity thus allowing for a safer surgical extirapation. ${ }^{120}$ Multiple reports established that the response of HPCs to RT (different schedules) is dose dependent. ${ }^{30}$ Total treatment doses of at least $45 \mathrm{~Gy}$ were shown to result in significantly superior local control rates. ${ }^{24}$ Current common schedules deliver a total of 45-52 Gy doses over 25-35 fractions. SRT (a hybrid technique halfway between EBRT and SRS discussed later) can also serve as a potent salvage strategy for the treatment of recurrent intracranial HPCs. ${ }^{3,25,47}$ Unlike the stereotactic-focused techniques mentioned, EBRT has a leading role in treating patients with a diffuse HPC disease and widespread cranial/brain involvement.

The role of EBRT in the management of spinal HPC is controversial as well, and opinions vary. Chou et al. ${ }^{77}$ reported in 2009 on a series of 16 patients with spinal HPCs who received adjuvant EBRT. In this cohort, EBRT had no effect on any of the different outcome parameters measured, mainly local recurrence. The histopathologic grade was the only prognostic factor deemed significant for recurrence. ${ }^{77}$ This is a very small cohort, and any statistical analyses-based conclusions should be taken with a grain of salt (or skepticism), yet similar conclusions were drawn by other groups such as Liu et al. ${ }^{89}$ or Payne et al. ${ }^{103}$ in 2000.

\section{Stereotactic Radiosurgery}

The role of SRS in treating various malignant and metastatic tumors is undeniable. ${ }^{121}$ HPCs share different traits making this lesion well suited for SRS, such as well-defined margins from clear radiographic delineation, the potential for residual and recurrent tumor, ${ }^{1}$ surgically challenging intracranial location (adjacent to crucial structures), and small volume lesions in unreachable locations. ${ }^{24}$ Treating HPCs with SRS [with either a Gamma Knife system (Elekta AB) or CyberKnife (Accuray)] has been described extensively, with reported tumor control rates ranging $46-100 \% .^{10,14,17,24,25,28,47,98,103,115,120}$ Of note, most reports are of small cohorts, single-center retrospective series, with only a few case series describing $>20$ patients, thus limiting the validity of any statistical analysis. ${ }^{122,123}$ A comprehensive search reveals a total of 17 studies now published reporting the utility of SRS for recurrent and residual HPC, summarized in Table 2. ${ }^{10,14,17,24,27,28,47,98,103,104,106,115,124-127}$ The first of the reports is by Coffey et al. ${ }^{14}$ describing a small cohort of 11 lesions in five patients, all receiving prior craniotomy (three also received prior EBRT with doses of 50-53 Gy). Prescribed margin doses reported ranged $12-18 \mathrm{~Gy}$, and the mean follow-up period was 14.8 months. Eight of the nine treated tumors decreased in size significantly. ${ }^{14}$ An overlapping cohort of 10 patients and 20 lesions was reported by Galanis et al. ${ }^{17}$ (including the 5 patients 


\section{Table 2: Cranial hemangiopericytoma SRS series}

\begin{tabular}{|c|c|c|c|c|c|c|}
\hline Series & Year & $n$ & Lesions & Margin dose ${ }^{+}$ & Follow up* & $\begin{array}{l}\text { Local tumor control } \\
(\%)^{* *}\end{array}$ \\
\hline Coffey $^{14}$ & 1993 & 5 & 11 & 15.5 & 14.8 & 81.8 \\
\hline Galanis $^{17}$ & 1998 & 10 & 20 & $12-18$ & $6-36$ & N/A \\
\hline Payne $^{103}$ & 2000 & 10 & 12 & 14 & 24.8 & 75 \\
\hline Sheehan $^{28}$ & 2002 & 14 & 15 & 15 & 31.3 & 79 \\
\hline Chang $^{24}$ & 2003 & 8 & 8 & 20.5 & 44 & 75 \\
\hline Ecker $^{98}$ & 2003 & 15 & 45 & 16 & 45.6 & 93 \\
\hline $\mathrm{Kano}^{27}$ & 2008 & 20 & 29 & 15 & 37.9 & 72.4 \\
\hline $\operatorname{Sun}^{115}$ & 2009 & 22 & 58 & 13.5 & 26 & 89.7 \\
\hline Iwai $^{124}$ & 2009 & 8 & 13 & 15.1 & 61 & 100 \\
\hline Olson $^{47}$ & 2010 & 21 & 28 & 17 & 69 & 46.4 \\
\hline $\operatorname{Kim}^{106}$ & 2010 & 9 & 17 & 18.1 & 34 & 82.4 \\
\hline Veeravagu $^{136}$ & 2010 & 14 & 24 & 21.2 & 37 & 81.8 \\
\hline Tsugawa $^{127}$ & 2013 & 7 & $10-28$ & 16.5 & 52.1 & $100,92,69.7^{++}$ \\
\hline \multirow[t]{2}{*}{ Chen $^{126}$} & \multirow[t]{2}{*}{2015} & \multirow[t]{2}{*}{38} & \multirow[t]{2}{*}{-} & $\mathrm{RT}(n=27)$ & \multirow[t]{2}{*}{61} & \multirow[t]{2}{*}{$26-55$} \\
\hline & & & & SRS $(n=11)$ & & \\
\hline Cohen-Inbar ${ }^{10}$ & 2015 & 90 & 133 & 15 & 59 & 54.8 \\
\hline $\mathrm{Joo}^{125}$ & 2016 & 1 & 2 & WBRT, SRS & 156 & No recurrence \\
\hline \multirow[t]{2}{*}{$\operatorname{Kim}^{104}$} & \multirow[t]{2}{*}{2017} & \multirow[t]{2}{*}{18} & \multirow[t]{2}{*}{40} & \multirow[t]{2}{*}{$17(13-25)$} & 46.9 & \multirow[t]{2}{*}{80} \\
\hline & & & & & $(3.3-137.7)$ & \\
\hline
\end{tabular}

$\mathrm{WBRT}=$ whole brain radiotherapy; $\mathrm{RT}=$ radiotherapy; $\mathrm{SRS}=$ stereotactic radiosurgery.

${ }^{+}$Gy.

*Median, months.

**At the last follow-up.

${ }^{++}$At 1,3 , and 5 years, respectively.

reported by Coffey et al. ${ }^{14}$ ), treated with salvage SRS (12-18 Gy). In this cohort seven patients failed prior EBRT 30.6-64 Gy, and all treated lesions showed volume control after SRS (14 decreased in size, 4 disappeared, 2 stable in size). ${ }^{17}$ Tian et al. ${ }^{128}$ noted that when HPC recurrence is diagnosed before age 35 years, this serves as a significant negative prognostic predictor of an earlier second relapse and shorter OS. ${ }^{128}$ Payne et al. ${ }^{103}$ reported a cohort of 12 patients (15 HPC lesions) treated with a mean prescription dose of $14 \mathrm{~Gy}(2.8-25 \mathrm{~Gy})$. During a mean clinical follow-up period of 24.8 months, nine lesions decreased in size and three lesions remained stable. Of note, late progression was noted after 22 months. ${ }^{103}$

Sheehan et al. ${ }^{28}$ reported a cohort of 14 patients harboring 15 lesions treated with SRS. This patient cohort underwent a total of 27 prior craniotomies and 7 EBRT courses (total doses of 30-61 Gy, mean 47.3 Gy). The salvage SRS prescription dose was 11-20 Gy, and the follow-up period was 5-76 months (average 31.3). Tumor regression (volume reduction) was shown in 12/15 lesions. The 5-year local tumor control and survival rates were $76 \%$ and $100 \%$, respectively, and DNM was reported in $29 \%$. A mean prescription (margin) dose $>15$ Gy was shown to result in $>50 \%$ reduction of tumor volume in $80 \%$ of patients. ${ }^{28}$ Similar conclusions can be found in a report by Kano et al. ${ }^{27}$ of a cohort of 20 patients (29 lesions) treated with SRS. The authors reported significantly better PFS $(p=0.0023)$ when patients were treated with a margin dose $>14$ Gy, with a 5-year PFS of $75.4 \%$ versus $56.3 \%$, respectively $(p=0.0023) .^{27}$ DNM or ENM developed in 79.2 (range 12.2-158.3) months on average after the initial diagnosis. Local tumor control rates (volume reduction or stability) were $72.4 \%(n=21), 20 \%(n=4)$ died of DNM, and $5 \%(n=1)$ died of ENM (liver and lung). Complete resolution was noted in $17.2 \%(n=5)$ of the WHO-II HPCs. ${ }^{27}$ Chang and Sakamoto $^{24}$ reported the use of a higher prescription dose (16-24 Gy, mean 20.5 Gy) in a cohort of eight HPC patients, achieving a $75 \%(n=6)$ tumor reduction rates during a mean follow-up of 44 months (range 8-77). ${ }^{24}$ Ecker et al. ${ }^{98}$ reported a cohort of 38 patients ( $n=22$ grade-II, $n=16$ grade-III HPCs), all treated with EBRT with or without SRS. ${ }^{50}$ A grade-III HPC histology was shown to result in recurrence significantly earlier ( 3.3 vs. 10 years, $p=0.004$ ). The authors concluded that harnessing SRS for the treatment of recurrent disease contributed to a better OS. $^{98}$

Melone et al. $^{7}$ reported a series of 36 HPCs. The actuarial 5- and 10-year recurrence rates were $50 \%$ and $72 \%$, respectively. Adjuvant ionizing radiation (all modalities, mean prescription dose $16 \mathrm{~Gy}$ ) was shown to significantly decrease the rates of recurrence $(p=0.04)$, not improving OS $(p=0.2){ }^{7}$ Kim et al. ${ }^{104}$ recently published a retrospective analysis of 18 patients (WHO-II = 8, WHO-III = 10) and 40 lesions (WHO-II = 13, WHO-III = 27) treated with SRS. The median OS was 134.7 

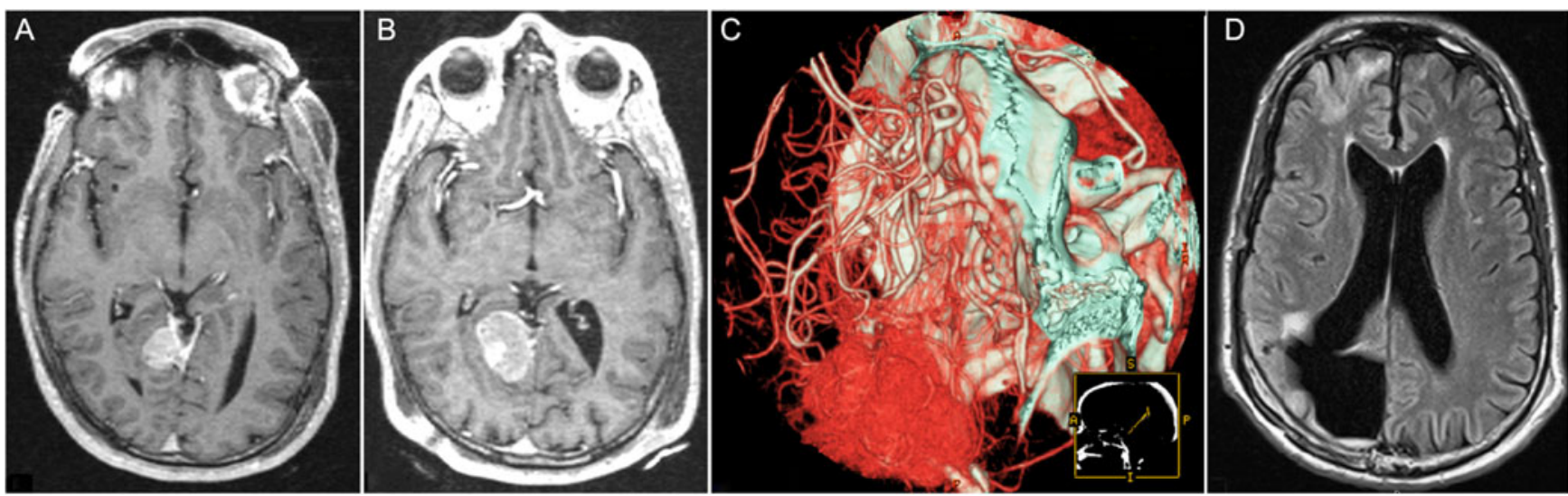

Figure 1: Sample Patient, Hemangiopericytoma. (A) Axial T1WI with gadolinium taken on the day of stereotactic radiosurgery (SRS) for a right tentorial hemangiopericytoma, s/p 1 surgical resection, 4/2002. (B) Axial T1WI with gadolinium taken on the day of repeat SRS for the same lesion, 12/2005. (C) CT-angio reconstruction pre-embolization and second surgical resection of the same lesion due to progression, 6/2009. (D) Follow-up images, 20 months after the second surgical resection, in T1WI-FLARE, showing final local control, 02/2011. Adapted from Cohen-Inbar et al. ${ }^{\circ}$

months, and the actuarial survival rates at 1,5 , and 10 years were $85.6 \%, 85.6 \%$, and $37.4 \%$, respectively. Local tumor control was $80 \%(n=32)$, and the average local recurrence-free interval (per lesion) for WHO-II and WHO-III were 86.1 and 40.5 months, respectively $(p=0.010)$. ENM developed in seven $(38.9 \%)$ patients with WHO-III HPCs. ${ }^{104}$

Jeon et al. ${ }^{129}$ recently reported on the efficacy of adjuvant RT in a cohort of 49 patients with intracranial HPC. Of the cohort, 31 patients received adjuvant RT after surgery, 26 with EBRT and 5 with SRS (Gamma Knife). The median follow-up period was 50 months (range 3-216). The authors concluded that local tumor control was better with GTR followed by RT than GTR alone $(p=0.056)$, with no difference in OS. Local tumor control and OS after STR + RT were equivalent to those after GTR alone. Tumor volume $>40 \mathrm{~cm}^{3}$ was associated with poor PFS $(p=0.024){ }^{129}$

In 2015, we reported the largest HPC cohort to date, a collaborative effort through the International Gamma Knife Research Foundation (IGKRF), done in an attempt to study outcomes of SRS for HPCs. ${ }^{10}$ Eight centers pooled patients together to form a cohort of 90 patients and 133 discrete lesions (78.9\% $n=71$ WHO-II, $21.1 \% n=19$ WHO-III). Prior treatment modalities included embolization $(n=8)$, chemotherapy $(n=2)$, and $\operatorname{EBRT}(n=34)$. The median tumor volume was $4.9 \mathrm{~cm}^{3}$ $\left(0.2-42.4 \mathrm{~cm}^{3}\right)$, the median prescription dose was $15 \mathrm{~Gy}$ (2.8-24 Gy), and the median follow-up period was 59 months (range 6-190). Local tumor control was noted in 55\% of tumors and $62.2 \%$ of patients. DNM was noted in $27.8 \%$ of patients, and ENM was noted in $24.4 \%$. The actuarial OS at 2, 4, 6, 8, and 10 years was $91.5 \%, 82.1 \%, 73.9 \%, 56.7 \%$, and $53.7 \%$ respectively. Local PFS at 2, 4, 6, 8, and 10 years was $81.7 \%, 66.3 \%, 54.5 \%$, $37.2 \%$, and $25.5 \%$, respectively, after initial SRS (Figure 1). ${ }^{10}$

There are no cohort reports on outcome after SRS for spinal HPC, rather a few isolated case reports, all depicted and described in Table $1 .{ }^{52-96}$ Our understanding on the role of SRS in treating spinal HPC is based on the cranial HPC's series reports. The patient-friendly design and supporting science and data of SRS makes this a valuable tool in our armamentarium, and future studies are required to directly prove its role in the management of spinal HPC.

\section{Distant Neural Metastasis}

The incidence of DNM varies widely in reports, ranging $14-63.6 \%{ }^{10,14,28,47,103,106,115}$ We reported a $27.8 \%(n=25)$ incidence of DNM, ${ }^{10}$ whereas Kim et al. reported a $44.4 \%$ (19 lesions in eight patients). ${ }^{104}$ The WHO pathological grade strongly affects the risk of DNM (37.5\% in grade-II and 50\% in grade-III). One important clinical implication stemming from the different reports is that new DNM lesions (i.e., out-of-field recurrence) can be effectively treated with additional SRS sessions. Since the cumulative long-term risk of DNM development is high, a vigilant radiographic and clinical follow-up visit schedules are mandated. ${ }^{104}$

\section{Extra-Neural Metastasis}

HPCs are notorious for sending ENM, unlike most other primary brain neoplasms. Common ENM HPC sites are the liver, lung, bones, abdominal cavity, kidney, and pancreas. ${ }^{4}$ The incidence of ENM ranges 11.1-25.0\% in different reports with a lag time of 8-16 years after initial diagnosis. ${ }^{104,130}$ We reported an ENM incidence of $24.4 \%(n=22)$, located in the liver, lung, kidney, bone, bowel, and external auditory canal. In our series, the median time to ENM was 21.5 months (range 3-108 months). ${ }^{10} \mathrm{Kim}$ et al. ${ }^{104}$ reported a series with impressive follow-up durations, which may explain the unusually high reported ENM rates of $38.9 \%$. One clear observation is that ENM serves as a late event in HPC disease course, related to histopathological grading (more prevalent in Grade-III HPC's), ${ }^{104}$ serving as a negative prognosticator and an harbinger of treatment failure. ENM is an accepted negative indicator of diminished OS, with a mean 24 months after ENM identification. ${ }^{24}$ Therefore, a vigilant long-term systemic surveillance for ENM is pivotal, in addition to local and DNM surveilance.

\section{Prognostic Factors Associated with Tumor Control and Overall Survival}

When reviewing parameters that influence tumor local control rates' OS, many such parameters suggested in shorter follow-up series do not maintain their statistical significance in longer follow-up series. We reported two major tumor- and 
treatment-related parameters that were shown to be significant and prognostic: prescription margin dose $>16 \mathrm{~Gy}(p=0.037$, 95\% CI $0.224-0.956$ for univariate analysis; $p=0.039,95 \% \mathrm{CI}$ 0.194-0.968 for multivariate analysis), and tumor grade ( $p=0.006$; 95\% CI $0.1382-6.616$ for univariate analysis; $p=0.011,95 \%$ CI 1.047-5.045 for multivariate analysis). Target SRS volume (i.e., tumor volume) was shown to be prognostic only in univariate analysis $(p=0.048)$, but bear in mind that this report focused on single-session SRS session, thus inherently featuring volume constraints (typically less than $10 \mathrm{ml}$ for singlesession SRS, median volume $4.9 \mathrm{~cm}^{3}$ in our series). ${ }^{10}$ In our multicenter series, ${ }^{10}$ OS was influenced solely by ENM presence $(p=0.029,95 \%$ CI $1.103-6.323)$. WHO grade was reported by others to influence OS. ${ }^{104}$

\section{Treatment of Local Tumor Recurrence}

HPCs' aggressive and relentless nature portrays a poor prognosis, one in which recurrence is the rule, not the exception. Thus, most patients will require more than one treatment modality. ${ }^{10}$ Patients in good physical condition and low operative risk, harboring a potentially resectable recurrent disease, should be considered for repeat microsurgical resection. ${ }^{103}$ Such surgical challenges have added complications and risk of reoperation to a vascular lesion, on top of common surgical risks and complications. Wang et al. recently reported ${ }^{131}$ a cohort of 57 patients with recurrent HPC (grades II-III), treated during 2008-2016. At the first recurrence, 30 patients $(52.6 \%)$ underwent surgery, 25patients $(43.9 \%)$ declined surgery, and 2 patients $(3.5 \%)$ received Gamma Knife treatment. The 1-, 3-, and 5-year actuarial rates of second PFS was $73.3 \%, 46.7 \%$, and $24.9 \%$, respectively, for HPC grade-II and $66.7 \%, 66.7 \%$, and $0 \%$, for HPC grade-III, respectively. The actuarial 1-, 3-, and 5-year OS after the first recurrence were $87.4 \%, 69.2 \%$, and $39.5 \%$ for HPC grade-II and $85.2 \%, 45.9 \%$, and $24.5 \%$ for HPC grade-III, respectively. Each 1-month increase in the time interval from first surgery to first recurrence (first recurrence-free survival) (HR, 0.972; 95\% CI, $0.952-0.993 ; p=0.010$ ) was noted to be strongly associated with better OS. Patients who received surgery with or without radiation at their first recurrence survived longer than patients who did not (53.0 vs. 35.7 months; $p=0.028) .{ }^{131}$ Thus, the decision to recommend reoperation in these should carefully balance tumorrelated features, patient-related features, patient and surgeon's inclinations, and always be preceded by an honest and complete patient consult. Alternatively, the hyper-vascular nature of HPCs suggests that immunotherapeutic antiangiogenic strategies (e.g., bevacizumab) might be another feasible option, although results are scarce and quite disappointing in recurrent HPC treatment as of now. ${ }^{98}$ Still, this concept is attractive since no SRS treatment can prevent DNM. ${ }^{27,28,103,106}$

Repeat SRS has been utilized in the treatment of recurrent HPC, yet the optimal dosing is still a matter of debate, balancing the higher risk of adverse radiation effects to the desire to achieve tumor volume control (both increase with increasing dose). ${ }^{115}$ The mean prescription doses reported for repeat SRS range 13.5-17 Gy. ${ }^{14,17,24,27,28,47,98,103,115,122,132}$ Olson et al. ${ }^{47}$ reported PFS rates of $90 \%, 60.3 \%$, and $28.7 \%$ at 1,3 , and 5 years after initial SRS, respectively. These rates improved to $95 \%, 71.5 \%$, and $71.5 \%$ at 1,3 , and 5 years after multiple SRS treatments. ${ }^{47}$ We reported a cohort of 32 patients receiving 48 repeat SRS procedures for 76 lesions, of which 17 lesions were true recurrences (in-field), whereas 59 were DNM. ${ }^{10}$ With a median prescription dose of $14 \mathrm{~Gy}$ (range 12-16 Gy), the actuarial PFS at $2,4,6$, and 8 years was $89 \%, 77 \%, 64 \%$, and $54 \%$ after a second SRS treatment, respectively. ${ }^{10}$

\section{Summary}

Treating patients harboring cranial HPCs remains a partially answered challenge, owing to these lesions' aggressive behavior. Resection (GTR when feasible and safe) remains the initial treatment option. ${ }^{133}$ For spinal HPCs, compartment location (ED/ID, IM/EM) coupled with histological grade is a crucial tumor-related parameter. Patient neurological functioning and overall health is another such parameter. Patients receiving surgery (GTR/STR) and RT (different modalities) show improved OS and PFS as compared to surgery alone or biopsy. We practice routine SRS or SBRT to the surgical bed even after GTR, as is a common practice in other malignant lesions (brain metastases, etc.). In many cases, patient-related comorbidities and tumor parameters (adjacent structures, skull-base location, etc.) preclude a GTR. EBRT or SRS does not impact OS in HPC patients. Their benefits are clearly limited to improved local tumor volume control and neurologic function, not affecting DNM or ENM development. In this scope SRS/ EBRT proves effective and safe and is thus supported by these authors, for both grade-II and grade-III HPCs. ${ }^{24,28,133} \mathrm{Kim}$ et al. ${ }^{134}$ recently reported a retrospective study of outcome in SFT-HPC in a cohort of 10 SFTs, 33 HPC-grade II, and 4 HPC grade-III. Mean and median follow-ups were 114.6 and 94.7 months, respectively (range 7.1-366.7). GTR was shown to significantly positively affect PFS and OS $(p=0.012)$, and SRS/EBRT versus none led to significantly longer PFS $(p=0.018)$. SRS provides acceptable rates of local tumor volume control coupled with treatment safety and a patient-friendly apparatus and procedure. Single-session SRS is most effective for lesions measuring $<2 \mathrm{~cm}$ their largest diameter or $10-12 \mathrm{~cm}^{3},{ }^{10,30}$ prescribing a margin dose of at least $15 \mathrm{~Gy} .{ }^{135}$ SRS leads to tumor volume control and neurological stability in most patients. ${ }^{10}$ For larger lesions, one may consider hypofractionated SRS or conventional EBRT. The management of recurrent intracranial HPC's disease management must be tailored to the size and location of a specific lesion and to the overall systemic disease burden. ${ }^{30}$ Repeat GTR can be attempted yet in most cases, and a planned STR followed by interval planned SRS is safer and more effective (AHS approach). ${ }^{107}$ Smaller recurrent HPC lesions can be adequately controlled with repeat or upfront SRS alone. ${ }^{10,30}$ EBRT can serve a palliative role in widespread disease.

A key component to patient care lies in vigilant clinical and radiographic follow-up visit schedule. Close follow-up imaging schedules and an alert team unequivocally lead to early detection of tumor recurrence, ENM or DNM development. Early detection benefits patients allowing to target smaller tumor volumes, making adjuvant SRS an even more attractive option. Follow-up intervals of 6 months seem prudent and sufficient. Since local recurrences, DNM, and ENM may develop many years after the initial diagnosis, follow-up should proceed indefinitely.

\section{CONFLict of InTEREST}

The author has no conflicts of interest to declare. 


\section{REFERENCES}

1. Tashjian VS, Khanlou N, Vinters HV, et al. Hemangiopericytoma of the cerebellopontine angle: a case report and review of the literature. Surg Neurol. 2009;72(3):290-5.

2. Goellner JR, Laws ER Jr, Soule EH, et al. Hemangiopericytoma of the meninges. Mayo Clinic experience. Am J Clin Pathol. 1978;70(3):375-80.

3. Guthrie BL, Ebersold MJ, Scheithauer BW, et al. Meningeal hemangiopericytoma: histopathological features, treatment, and long-term follow-up of 44 cases. Neurosurgery. 1989;25(4): 514-22.

4. Mena H, Ribas JL, Pezeshkpour GH, et al. Hemangiopericytoma of the central nervous system: a review of 94 cases. Hum Pathol. 1991;22(1):84-91.

5. Bailey P, Cushing H, Eisenhardt L. Angioblastic meningioma. Arch Pathol. 1928;6(10):953-90.

6. Laviv Y, Thomas A, Kasper EM. Hypervascular lesions of the cerebellopontine angle: the relevance of angiography as a diagnostic and therapeutic tool and the role of stereotactic radiosurgery in management. A comprehensive review. World Neurosurg. 2017;100:100-17.

7. Melone AG, D'Elia A, Santoro F, et al. Intracranial hemangiopericytoma - our experience in 30 years: a series of 43 cases and review of the literature. World Neurosurg. 2014;81(3-4):556-62.

8. Bose B. Hemangiopericytoma: a clinicopathologic and ultrastructure study. World J Surg. 1981;5(6):863-71.

9. Ben Nsir A, Badri M, Kassar AZ, et al. Hemangiopericytoma of the cerebellopontine angle: a wolf in sheep's clothing. Brain Tumor Res Treat. 2016;4(1):8-12.

10. Cohen-Inbar O, Lee CC, Mousavi SH, et al. Stereotactic radiosurgery for intracranial hemangiopericytomas: a multicenter study. J Neurosurg. 2017;126(3):744-54.

11. Sonabend AM, Zacharia BE, Goldstein $\mathrm{H}$, et al. The role for adjuvant radiotherapy in the treatment of hemangiopericytoma: a surveillance, epidemiology, and end results analysis. J Neurosurg. 2014;120(2):300-8.

12. Begg CF, Garret R. Hemangiopericytoma occurring in the meninges: case report. Cancer. 1954;7(3):602-6.

13. Giannini C, Rushing EJ, Hainfellner JA. Haemangiopericytoma. In: Louis DN, Ohgaki H, Wiestler OD, Cavenee WK, editors. WHO classification of tumours of the central nervous system, 4th ed. Lyon: IARC Press; 2007, pp. 178-80.

14. Coffey RJ, Cascino TL, Shaw EG. Radiosurgical treatment of recurrent hemangiopericytomas of the meninges: preliminary results. J Neurosurg. 1993;78(6):903-8.

15. Ramsey HJ. Fine structure of hemangiopericytoma and hemangioendothelioma. Cancer. 1966;19(12):2005-18.

16. Louis DN, Perry A, Reifenberger G, et al. The 2016 World Health Organization classification of tumors of the central nervous system: a summary. Acta Neuropathol. 2016;131(6):803-20.

17. Galanis E, Buckner JC, Scheithauer BW, et al. Management of recurrent meningeal hemangiopericytoma. Cancer. 1998;82(10): 1915-20.

18. Vuorinen V, Sallinen P, Haapasalo H, et al. Outcome of 31 intracranial haemangiopericytomas: poor predictive value of cell proliferation indices. Acta Neurochir (Wien). 1996;138(12):1399-408.

19. Jaaskelainen J, Servo A, Haltia M, et al. Intracranial hemangiopericytoma: radiology, surgery, radiotherapy, and outcome in 21 patients. Surg Neurol. 1985;23(3):227-36.

20. Schroder R, Firsching R, Kochanek S. Hemangiopericytoma of meninges. II. General and clinical data. Zentralbl Neurochir. 1986;47(3):191-9.

21. Chan JK, Cheuk W, Ho LC, et al. Recurrent meningeal hemangiopericytoma with multiple metastasis and hypoglycemia: a case report. Case Rep Med. 2012;2012:628756.

22. Rutkowski MJ, Jian BJ, Bloch O, et al. Intracranial hemangiopericytoma: clinical experience and treatment considerations in a modern series of 40 adult patients. Cancer. 2012;118(6):1628-36.

23. Erdag G, Qureshi HS, Patterson JW, et al. Solitary fibrous tumors of the skin: a clinicopathologic study of 10 cases and review of the literature. J Cutan Pathol. 2007;34(11):844-50.
24. Chang SD, Sakamoto GT. The role of radiosurgery for hemangiopericytomas. Neurosurg Focus. 2003;14(5):e14.

25. Dufour H, Metellus P, Fuentes S, et al. Meningeal hemangiopericytoma: a retrospective study of 21 patients with special review of postoperative external radiotherapy. Neurosurgery. 2001; 48(4):756-63.

26. Ghia AJ, Chang EL, Allen PK, et al. Intracranial hemangiopericytoma: patterns of failure and the role of radiation therapy. Neurosurgery. 2013;73(4):624-31.

27. Kano H, Niranjan A, Kondziolka D, et al. Adjuvant stereotactic radiosurgery after resection of intracranial hemangiopericytomas. Int J Radiat Oncol Biol Phys. 2008;72(5):1333-9.

28. Sheehan J, Kondziolka D, Flickinger J, et al. Radiosurgery for treatment of recurrent intracranial hemangiopericytomas. Neurosurgery. 2002;51(4):905-11.

29. Rutkowski MJ, Sughrue ME, Kane AJ, et al. Predictors of mortality following treatment of intracranial hemangiopericytoma. J Neurosurg. 2010;113(2):333-9.

30. Schirmer CM, Heilman CB. Hemangiopericytomas of the skull base. Neurosurg Focus. 2011;30(5):E10.

31. Sibtain NA, Butt S, Connor SE. Imaging features of central nervous system haemangiopericytomas. Eur Radiol. 2007;17(7):1685-93.

32. Marc JA, Takei Y, Schechter MM, et al. Intracranial hemangiopericytomas. Angiography, pathology and differential diagnosis. Am J Roentgenol Radium Ther Nucl Med. 1975;125(4):823-32.

33. Zhou JL, Liu JL, Zhang J, et al. Thirty-nine cases of intracranial hemangiopericytoma and anaplastic hemangiopericytoma: a retrospective review of MRI features and pathological findings. Eur $\mathbf{J}$ Radiol. 2012;81(11):3504-10.

34. Liu G, Chen ZY, Ma L, et al. Intracranial hemangiopericytoma: MR imaging findings and diagnostic usefulness of minimum ADC values. J Magn Reson Imaging. 2013;38(5):1146-51.

35. Liu L, Yin B, Geng DY, et al. Comparison of ADC values of intracranial hemangiopericytomas and angiomatous and anaplastic meningiomas. J Neuroradiol. 2014;41(3):188-94.

36. He W, Xiao X, Li X, et al. Whole-tumor histogram analysis of apparent diffusion coefficient in differentiating intracranial solitary fibrous tumor/hemangiopericytoma from angiomatous meningioma. Eur J Radiol. 2019;112:186-91.

37. Merhemic Z, Stosic-Opincal T, Thurnher MM. Neuroimaging of spinal tumors. Magn Reson Imaging Clin N Am. 2016;24(3):563-79.

38. Ramdasi RV, Nadkarni TD, Goel NA. Hemangiopericytoma of the cervical spine. J Craniovertebr Junction Spine. 2014;5(2):95-8.

39. Zhang P, Hu J, Zhou D. Hemangiopericytoma of the cervicothoracic spine: a case report and literature review. Turk Neurosurg. 2014;24(6):948-53.

40. Landi A, Palmarini V, D'Elia A, et al. Magnetic resonance diffusion tensor imaging and fiber-tracking diffusion tensor tractography in the management of spinal astrocytomas. World J Clin Cases. 2016;4(1):1-4.

41. Patnaik S, Jyotsnarani Y, Uppin SG, et al. Imaging features of primary tumors of the spine: a pictorial essay. Indian J Radiol Imaging. 2016;26(2):279-89.

42. Alkherayf F, Arab AF, Tsai E. Conus medullaris teratoma with utilization of fiber tractography: case report. J Neurol Surg Rep. 2015;76(1):183-7.

43. Naito K, Yamagata T, Arima H, et al. Qualitative analysis of spinal intramedullary lesions using PET/CT. J Neurosurg Spine. 2015;31(5):1-7.

44. Millesi M, Kiesel B, Woehrer A, et al. Analysis of 5-aminolevulinic acid-induced fluorescence in 55 different spinal tumors. Neurosurg Focus. 2014;36(2):E11.

45. National Comprehensive Cancer Network Clinical Practice Guidelines: Central Nervous System Cancers v1.2016, Available at: https://www.nccn.org/professionals/physician_gls/default.aspx Accessed 22 October 2019.

46. Fountas KN, Kapsalaki E, Kassam M, et al. Management of intracranial meningeal hemangiopericytomas: outcome and experience. Neurosurg Rev. 2006;29(2):145-53.

47. Olson C, Yen CP, Schlesinger D, et al. Radiosurgery for intracranial hemangiopericytomas: outcomes after initial and repeat Gamma knife surgery. J Neurosurg. 2010;112(1):133-9. 
48. Hall WA, Ali AN, Gullett N, et al. Comparing central nervous system (CNS) and extra-CNS hemangiopericytomas in the surveillance, epidemiology, and end results program: analysis of 655 patients and review of current literature. Cancer. 2012;118(21):5331-8.

49. Ghia AJ, Allen PK, Mahajan A, et al. Intracranial hemangiopericytoma and the role of radiation therapy: a population based analysis. Neurosurgery. 2013;72(2):203-9.

50. Stessin AM, Sison C, Nieto J, et al. The role of postoperative radiation therapy in the treatment of meningeal hemangiopericytoma-experience from the SEER database. Int J Radiat Oncol Biol Phys. 2013;85(3):784-90.

51. Kumar R, Wani AA. Unusual tumors of the posterior fossa skull base. Skull Base. 2006;16(2):75-84

52. Schirger A, Uihlein A, Parker HL, et al. Hemangiopericytoma recurring after 26 years; report of case. Proc Staff Meet Mayo Clin. 1958;33(13):347-52.

53. Kruse F Jr. Hemangiopericytoma of the meninges (angioblastic meningioma of Cushing and Eisenhardt). Clinico-pathologic aspects and follow-up studies in 8 cases. Neurology. 1961; 11(9):771-7.

54. Pitlyk PJ, Dockery MB, Miller RH. Hemangiopericytoma of the spinal cord: report of three cases. Neurology. 1965;15(7):649-53.

55. Kriss FC, Kahn DR, Schneider RC. Value of angiography in intraspinal mediastinal hemangiopericytoma. Case report. J Neur osurg. 1968;29(5):535-9.

56. Fathie K. Hemangiopericytoma of the thoracic spine; case report. J Neurosurg. 1970;32(3):371-4.

57. Gerner RE, Moore GE, Pickren JW. Hemangiopericytoma. Ann Surg. 1974;179(2):128-32.

58. Scott M, Kellett G, Peale A. Angioblastic meningioma (hemangiopericytoma) of the cerebellar fossa with metastasis to the temporal bone and the lumbar spine. Surg Neurol. 1974;2(1):35-8.

59. Harris DJ, Fornasier VL, Livingston KE. Hemangiopericytoma of the spinal canal. Report of three cases. J Neurosurg. 1978; 49(6):914-20.

60. Stern MB, Grode ML, Goodman MD. Hemangiopericytoma of the cervical spine: report of an unusual case. Clin Orthop Relat Res. 1980;151:201-4.

61. Cappabianca P, Maiuri F, Pettinato G, et al. Hemangiopericytoma of the spinal canal. Surg Neurol. 1981;15(4):298-302.

62. Muraszko KM, Antunes JL, Hilal SK, et al. Hemangiopericytomas of the spine. Neurosurgery. 1982;10(4):473-9.

63. Ciappetta P, Celli P, Palma L, et al. Intraspinal hemangiopericytomas. Report of two cases and review of the literature. Spine. 1985;10(1):27-31.

64. Bridges LR, Roche S, Nashef L, et al. Haemangiopericytic meningioma of the sacral canal: a case report. J Neurol Neurosurg Psychiatry. 1988;51(2):288-90.

65. Salvati M, Ciappetta P, Artico M, et al. Intraspinal hemangiopericytoma: case report and review of the literature. Neurosurg Rev. 1991;14(4):309-13.

66. Nonaka M, Kohmura E, Hirata M, et al. Metastatic meningeal hemangiopericytoma of thoracic spine. Clin Neurol Neurosurg. 1998;100(3):228-30.

67. Akhaddar A, Chakir N, Amarti A, et al. Thoracic epidural hemangiopericytoma. Case report. J Neurosurg Sci. 2002;46(2):89-92.

68. Betchen S, Schwartz A, Black C, et al. Intradural hemangiopericytoma of the lumbar spine: case report. Neurosurgery. 2002;50(3):654-7.

69. Ijiri K, Yuasa S, Yone K, et al. Primary epidural hemangiopericytoma in the lumbar spine: a case report. Spine. 2002;27(7): E189-92.

70. Woitzik J, Sommer C, Krauss JK. Delayed manifestation of spinal metastasis: a special feature of hemangiopericytoma. Clin Neurol Neurosurg. 2003;105(3):159-66.

71. Mohammadianpanah M, Torabinejad S, Bagheri MH, et al. Primary epidural malignant hemangiopericytoma of thoracic spinal column causing cord compression: case report. Sao Paulo Med J. 2004; 122(5):220-2.

72. Lee JK, Kim SH, Joo SP, et al. Spinal metastasis from cranial meningeal hemangiopericytomas. Acta Neurochir (Wien). 2006; 148(7):787-90.
73. Zhao Y, Zhao JZ. Clinical and pathological characteristics of primary intraspinal hemangiopericytoma and choice of treatment. Chin Med J (Engl). 2007;120(2):115-9.

74. Kashiwazaki D, Hida K, Yano S, et al. Subpial hemangiopericytoma with marked extramedullary growth: case report. Neurosurgery. 2007;61(6):E1336-7.

75. Kumar R, Vaid VK, Kumar V, et al. Hemangiopericytoma of thoracic spine: a rare bony tumor. Childs Nerv Syst. 2007;23(10):1215-9.

76. Taniura S, Taniguchi M, Mizutani T, et al. Metastatic hemangiopericytoma to the cauda equine: a case report. Spine. 2007;7(3):371-3.

77. Chou CW, Hsu SP, Lin SC, et al. Primary intradural hemangiopericytoma with intramedullary invasion. J Chin Med Assoc. 2009;72(10):536-41.

78. Hogle WP. Malignant hemangiopericytoma: a clinical overview and case study. Clin J Oncol Nurs. 2003;7(1):57-62.

79. Cole CD, Schmidt MH. Hemangiopericyomas of the spine: case report and review of the literature. Rare Tumors. 2009;43(2):132-6.

80. Fukuda Y, Watanabe K, Toyama Y, et al. Metastasis of intracranial meningeal hemangiopericytoma to thoracic spine 17 years after surgical excision: a case report. J Orthop Sci. 2015;20(2):425-9.

81. Moscovici S, Ramirez-DeNoriega F, Fellig Y, et al. Intradural extramedullary hemangiopericytoma of the thoracic spine infiltrating a nerve root: a case report and literature review. Spine. 2011;36(23):1534-9.

82. Ackerman PD, Khaldi A, Shea JF. Intradural hemangiopericytoma of the thoracic spine: a case report. Spine J. 2011;11(7):e9-14.

83. Santillan A, Zink W, Lavi E, et al. Endovascular embolization of cervical hemangiopericytoma with Onyx-18: case report and review of the literature. J Neurointerv Surg. 2011;3(3):304-7.

84. Torigoe K, Akai T, Iida T. Hemangiopericytoma on the intradural thoracic spinal cord: a case report. No Shinkei Geka. 2012;40(4):351-7.

85. Nakashima H, Imagama S, Sakai Y, et al. Dumbbell-type hemangiopericytoma in the cervical spine: a case report and review. J Orthop Sci. 2013;18(5):849-55.

86. Shirzadi A, Drazin D, Gates M, et al. Surgical management of primary spinal hemangiopericytomas: an institutional case series and review of the literature. Eur Spine J. 2013;22(Suppl 3): S450-9.

87. Drazin D, Shweikeh F, Bannykh S, et al. Hemangiopericytoma invading the craniovertebral junction: first reported case and review of the literature. J Craniovertebr Junction Spine. 2013; $4(1): 32-4$.

88. Lee CH, Kim KJ, Jahng TA, et al. Spinal hemangiopericytoma which needed intraoperative embolization due to unexpected bleeding. J Korean Neurosurg Soc. 2013;54(3):253-6.

89. Liu H, Yang A, Chen N, et al. Hemangiopericytomas in the spine: clinical features, classification, treatment, and long-term follow-up in 26 patients. Neurosurgery. 2013;72(1):16-24.

90. Jayashankar E, Prabhala S, Raju S, et al. Recurrent extradural hemangiopericytoma of thoracic spine: a case report. Indian $\mathbf{J}$ Pathol Microbiol. 2014;57(4):603-5.

91. Kaur J, Pandit S, Sharma MC, et al. Intradural extra medullary hemangiopericytoma of dorsal spine. Childs Nerv Syst. 2015; 31(1):173-5.

92. Türk CÇ, Kara NN, Süren D, et al. Distinctive characteristic features of intramedullary hemangiopericytomas. Asian Spine J. 2015; 9(4):522-8.

93. Das A, Singh P, Suri V, et al. Spinal hemangiopericytoma: an institutional experience and review of the literature. Eur Spine J. 2015;24(4):606-13.

94. Chew LS, Han XJ, Tan KK, et al. Hemangiopericytoma of the thoracic spine: a case report. J Surg Case Rep. 2017;7(7):1-4.

95. Kweh BTS, Pham C, McLean C, et al. Metastatic craniocervical hemangiopericytoma presenting with hydrocephalus and papilledema - Case review. J Clin Neurosci. 2018;56:186-7.

96. Sweid A, Noureldine MHA, Nasser S, et al. A case report of meningeal hemangiopericytoma: a 9-year journey from the brain to the spine. World Neurosurg. 2019;122:459-63.

97. Li Z, Deng Y, Li Z, et al. Primary epidural hemangiopericytoma of the thoracic spine: case report and literature review. J Clin Neurosci. 2019;60:142-7. 
98. Ecker RD, Marsh WR, Pollock BE, et al. Hemangiopericytoma in the central nervous system: treatment, pathological features, and long-term follow up in 38 patients. J Neurosurg. 2003;98(6): 1182-7.

99. Liu J, Cao L, Liu L, et al. Primary epidural hemangiopericytoma in the sacrum: a rare case and literature review. Tumor Biol. 2014;35(11):11655-8.

100. Beadle GF, Hillcoat BL. Treatment of advanced malignant hemangiopericytoma with combination adriamycin and DTIC: a report of four cases. J Surg Oncol. 1983;22(3):167-70.

101. Kim JH, Jung HW, Kim YS, et al. Meningeal hemangiopericytomas: long-term outcome and biological behavior. Surg Neurol. 2003;59(1):47-53.

102. Soyuer S, Chang EL, Selek U, et al. Intracranial meningeal hemangiopericytoma: the role of radiotherapy: report of 29 cases and review of the literature. Cancer. 2004;100(7):1491-7.

103. Payne BR, Prasad D, Steiner M, et al. Gamma surgery for hemangiopericytomas. Acta Neurochir (Wien). 2000;142(5): 527-36.

104. Kim BS, Kong DS, Seol HJ, et al. Gamma knife radiosurgery for residual or recurrent intracranial hemangiopericytomas. J Clin Neurosci. 2017;35:35-41.

105. Bassiouni H, Asgari S, Hübschen U, et al. Intracranial hemangiopericytoma: treatment outcomes in a consecutive series. Zentralbl Neurochir. 2007;68(3):111-8.

106. Kim JW, Kim DG, Chung HT, et al. Gamma knife stereotactic radiosurgery for intracranial hemangiopericytomas. J Neurooncol. 2010;99(1):115-22.

107. Cohen-Inbar O, Sviri GE. Adaptive hybrid surgery: paradigm shift for patient-centered Neurosurgery. Rambam Maimonides Med J. 2018;9(3):1-10.

108. Chacko G, Chacko AG, Rajshekhar V, et al. Intracranial hemangiopericytomas: correlation of topoisomerase Il alpha expression with biologic behavior. Surg Neurol. 2006;65(1):11-7.

109. Tso HK, Wang YC, Yang DY, et al. Intra-extracranial hemangiopericytoma: clinical manifestations, histopathological features, diagnosis, treatment, and outcomes. J Chin Med Assoc. 2002; 65:314-9.

110. Mathieu D. Why do hemangiopericytomas have such high recurrence rates? Expert Rev Anticancer Ther. 2016;16(11): 1095-6.

111. Chamberlain MC, Glantz MJ. Sequential salvage chemotherapy for recurrent intracranial hemangiopericytoma. Neurosurgery. 2008; 63(2):256-64.

112. Pierscianek D, Michel A, Hindy NE, et al. Activation of multiple angiogenic signaling pathways in hemangiopericytoma. Brain Tumor Pathol. 2016;33(3):200-8.

113. Michishita M, Uto T, Nakazawa R, et al. Antitumor effect of bevacizumab in a xenograft model of canine hemangiopericytoma. J Pharmacol Sci. 2013;121:339-42.

114. Park MS, Patel SR, Ludwig JA, et al. Activity of temozolomide and bevacizumab in the treatment of locally advanced, recurrent, and metastatic hemangiopericytoma and malignant solitary fibrous tumor. Cancer. 2011;117(21):4939-47.

115. Sun S, Liu A, Wang C. Gamma knife radiosurgery for recurrent and residual meningeal hemangiopericytomas. Stereotact Funct Neurosurg. 2009;87(2):114-9.

116. Park MS, Araujo DM. New insights into the hemangiopericytoma/ solitary fibrous tumor spectrum of tumors. Curr Opin Oncol. 2009;21(4):327-31.
117. Barquilla A, Pasquale EB. Eph receptors and ephrins: therapeutic opportunities. Annu Rev Pharmacol Toxicol. 2015;55:465-87.

118. Dube VE, Paulson JF. Metastatic hemangiopericytoma cured by radiotherapy. A case report. J Bone Joint Surg Am. 1974;56(4): $833-5$.

119. Mira JG, Chu FC, Fortner JG. The role of radiotherapy in the management of malignant hemangiopericytoma: report of eleven new cases and review of the literature. Cancer. 1977;39(3):1254-9.

120. Uemura S, Kuratsu J, Hamada J, et al. Effect of radiation therapy against intracranial hemangiopericytoma. Neurol Med Chir. 1992;32(6):328-32.

121. Sheehan J, Niranjan A, Flickinger JC, et al. The expanding role of neurosurgeons in the management of brain metastases. Surg Neurol. 2004;62(1):32-41.

122. Penel N, Amela EY, Decanter G, et al. Solitary fibrous tumors and so-called hemangiopericytoma. Sarcoma. 2012; 2012:690251.

123. Shinder R, Jackson TL, Araujo D, Prieto VG, Guadagnolo BA, Esmaeli B. Preoperative radiation therapy in the management of recurrent orbital hemangiopericytoma. Ophthal Plast Reconstr Surg. 2011;27(5):e126-8.

124. Iwai Y, Yamanaka K. Gamma knife radiosurgery for other primary intra-axial tumors. Prog Neurol Surg. 2009;22:129-41.

125. Joo MS, Rho YJ, Song SW, et al. Metastatic intracranial hemangiopericytoma to the spinal column: a case report. Brain Tumor Res Treat. 2016;4(2):128-32.

126. Chen LF, Yang Y, Yu XG, et al. Multimodal treatment and management of strategies of intracranial hemangiopericytoma. J Clin Neurosci. 2015;22(4):718-25.

127. Tsugawa T, Mori Y, Kobayashi T, et al. Gamma knife stereotactic radiosurgery for intracranial hemangiopericytoma. J Radiosurg SBRT. 2014;3(1):29-35.

128. Tian R, Hao S, Hou Z, et al. Clinical characteristics and prognostic analysis of recurrent hemangiopericytoma in the central nervous system: a review of 46 cases. J Neurooncol. 2013;115(1):53-9.

129. Jeon SH, Park SH, Kim JW, et al. Efficacy of adjuvant radiotherapy in the intracranial hemangiopericytoma. J Neurooncol. 2018;137(3):567-73

130. Koyama H, Harada A, Nakao A, et al. Intracranial hemangiopericytoma with metastasis to the pancreas. Case report and literature review. J Clin Gastroenterol. 1997;25(4):706-8.

131. Wang W, Zhang GJ, Zhang LW, et al. Long-term outcome and prognostic factors after repeated surgeries for intracranial hemangiopericytomas. World Neurosurg. 2017;107:495-505.

132. Alén JF, Lobato RD, Gómez PA, et al. Intracranial hemangiopericytoma: study of 12 cases. Acta Neurochir (Wien). 2001;143(6): 575-86.

133. Trifiletti DM, Mehta GU, Grover S, et al. Clinical management and survival of patients with central nervous system hemangiopericytoma in the National Cancer Database. J Clin Neurosci. 2017;44:169-74.

134. Kim BS, Kim Y, Kong DS, et al. Clinical outcomes of intracranial solitary fibrous tumor and hemangiopericytoma: analysis according to the $2016 \mathrm{WHO}$ classification of central nervous system tumors. J Neurosurg. 2018;129(6):1384-96.

135. Someya M, Sakata KI, Oouchi A, et al. Four cases of meningeal hemangiopericytoma treated with surgery and radiotherapy. Jpn J Clin Oncol. 2001;31(11):548-52.

136. Veeravagu A, Jiang B, Patil CG, et al. CyberKnife stereotactic radiosurgery for recurrent,metastatic, and residual hemangiopericytomas. J Hematol Oncol. 2011;6(1):26. 